\title{
Inhibition of metastatic potential in colorectal carcinoma in vivo and in vitro using immunomodulatory drugs (IMiDs)
}

\author{
WM Liu*,', JY Henry', B Meyer', JB Bartlett', AG Dalgleish' and C Galustian' \\ 'Division of Cellular and Molecular Medicine, Department of Oncology, St George's, University of London, London, UK; ' Celgene Corp., Summit, NJ, USA
}

\begin{abstract}
BACKGROUND: Thalidomide and lenalidomide are FDA approved for the treatment of multiple myeloma and, along with pomalidomide, are being investigated in various other cancers. Although these agents display immunomodulatory, anti-angiogenic and anti-apoptotic effects, little is known about their primary mode of therapeutic action in patients with cancer.

METHODS: As part of a continuing research effort, we have investigated the effects of these agents on the metastatic capacity of murine colorectal cancer cell lines both in vivo and in vitro. Allied to these, we have studied their effects on the molecular pathways associated with metastasis.

RESULTS: Results indicate that thalidomide, lenalidomide and pomalidomide significantly inhibit the metastatic capability of colorectal carcinoma cells. Anchorage-independent growth, used as a coarse indicator of transformation, was significantly reduced, as were migratory capacity and invasive competence. In addition, an in vivo experimental metastasis model also showed that treatment with the drugs resulted in a significantly lower number of metastatic pulmonary nodules relative to control mice. Allied to these cellular and phenotypic changes were alterations in molecular markers of metastasis and in intracellular signalling competency.

CONCLUSIONS: These results provide evidence that in addition to their immunomodulatory effects, thalidomide, lenalidomide and pomalidomide can impair the metastatic capacity of tumours, and that this mechanism may involve alterations to cell signalling functionality.

British Journal of Cancer (2009) I 01, 803-8I2. doi:I0.I038/sj.bjc.6605206 www.bjcancer.com

Published online 28 July 2009
\end{abstract}

(c) 2009 Cancer Research UK

Keywords: lenalidomide; pomalidomide; thalidomide; metastasis; VEGF

There is growing evidence supporting a role for thalidomidederived immunomodulatory drugs known as IMiDs in cancer therapy (Galustian et al, 2004; Bartlett et al, 2005; Shalapour et al, 2006; Melchert et al, 2007; Verhelle et al, 2007). This proprietary class of therapeutic analogues, as exemplified by lenalidomide (Revlimid, Celgene, Summit, NJ, USA, CC-5013) was developed on the basis of structural activity relationship studies focussing on molecular alterations to the central ring framework of the thalidomide molecule as an approach to enhancing the immunomodulatory characteristics of the agents (Stirling, 2001; Bartlett et al, 2004). Allied to this enhancement, IMiDs, such as thalidomide, display potent anti-proliferative, apoptotic and antiangiogenic properties both in vivo and in a wide spectrum of tumour cell lines (Dredge et al, 2002, 2005; Shalapour et al, 2006; Verhelle et al, 2007). At present, lenalidomide is approved by the US Food and Drug Administration for use in patients with myelodysplastic syndromes (associated with no or 5q-deletions), and in combination with dexamethasone in patients with multiple myeloma who have received one previous therapy (Dimopoulos et al, 2007; Weber et al, 2007). However, there is a growing list of other cancers, including non-small-cell lung cancer, pancreatic,

*Correspondence: Dr WM Liu, Division of Cellular and Molecular Medicine, Department of Oncology, St George's, University of London, 2nd Floor, Jenner Wing, London SWI7 ORE, UK;

E-mail:w.liu@sgul.ac.uk

Revised 29 June 2009; accepted 30 June 2009; published online 28 July 2009 thymic, rectal apocrine carcinomas and angiosarcoma, in which objective responses have been observed in monotherapy or in combination with other therapies (Sharma et al, 2006; Kalmadi et al, 2007; Liu et al, 2009a).

Despite the clinical merit of lenalidomide, the precise mechanism of its action remains unclear, as does the primary method of action whereby clinical activity is achieved. The inhibition of metastasis, a direct anti-tumour effect, and immunomodulation have all been associated with drug action, but the importance of each appears to be dependent on the cancer type - specifically the immune status of the patient and the molecular signature of the tumour. In fact, it is possible that this broad spectrum of action actually defines its clinical activity and appeal. For example, an important facet of thalidomide and indeed the IMiDs, is the ability to inhibit metastasis and angiogenesis (D'Amato et al, 1994; Kumar et al, 2004; Chanan-Khan and Cheson, 2008). This inhibition has been attributed to a number of modes of actions, and a definitive answer is unavailable.

Angiogenesis and metastasis are hallmarks of cancer and are processes that support and propagate the disease (Folkman, 1971; Hanahan and Weinberg, 2000). They correlate with and predict tumour stage for a number of neoplasms (Weidner et al, 1991, 1993; Jaeger et al, 1995; Yuan et al, 1995), and as a consequence, therapeutic approaches that inhibit them have been used successfully. There are currently limited in vitro data exploring the antimetastatic role of lenalidomide and pomalidomide in solid tumours, and those available have used combinations with other antiangiogenic agents (Mangiameli et al, 2007; Blansfield et al, 2008). 
Therefore, the primary aim of this study was to investigate the effects of IMiDs on the metastatic capability of tumours through both in vitro and in vivo approaches. Allied to this would be to study the effects the drugs would have on intracellular signalling pathways and how they correlated with the effects on biomarkers of metastasis.

\section{MATERIALS AND METHODS}

\section{Animals}

Female BALB/c and C57BL/6 mice were purchased from and maintained by the Biological Research Facility in a pathogen-free environment at St George's (University of London, London, UK). Animals were acclimatised for at least 7 days before each experiment and were used at the age of 9-13 weeks. All procedures were conducted in accordance with and approved by the Home Office of the United Kingdom.

\section{Cell culture}

The murine colorectal carcinoma (CRC) cell lines CT26 (syngeneic to $\mathrm{BALB} / \mathrm{c}$ ) and CMT93 (syngeneic to C57BL/6) were obtained from the Cancer Research UK Cell Production Laboratories (London, UK) and maintained in Dulbecco's modified Eagle's medium (DMEM; Sigma Ltd, Poole, UK) supplemented with $10 \%$ $(\mathrm{v} / \mathrm{v})$ fetal bovine serum (FBS), $2 \mathrm{~mm}$ L-glutamine and $1 \times$ penicillin/streptomycin (basal growth medium). All the cell lines were incubated in a humidified atmosphere with $5 \% \mathrm{CO}_{2}$ in air at $37^{\circ} \mathrm{C}$, and only cells with a passage number of $<10$ were used in the experiments.

\section{Reagents}

Thalidomide, lenalidomide and pomalidomide were obtained from Celgene Corp. (Summit, NJ, USA), and dissolved in DMSO to create $10 \mathrm{~mm}$ stock solutions that were maintained at $-20^{\circ} \mathrm{C}$ for no longer than 1 week. For in vivo studies, the drugs were dissolved in $0.5 \%$ DMSO in PBS and stored at $4{ }^{\circ} \mathrm{C}$ for the duration of the experiment.

\section{Proliferation assays}

To study the effects of thalidomide, lenalidomide and pomalidomide on cell growth, CT26 cells growing exponentially were added to 96 -well plates at a density of $5 \times 10^{4}$ per well. Drugs $(1-1000 \mu \mathrm{M})$ were then added to the wells, ensuring an equal volume of $200 \mu \mathrm{l}$ across the plates. Cell number/proliferation was measured at $72 \mathrm{~h}$ using a standard methylthiazoletetrazolium (MTT)-based assay without modifications. Briefly, MTT (Sigma Ltd) was added to each well to yield a working concentration of $0.4 \mathrm{mg} \mathrm{ml}^{-1}$, and the plates were returned to the incubator for a further $2 \mathrm{~h}$. After this time, the medium was aspirated, $200 \mu \mathrm{l}$ of DMSO was then added to each well and the plates were agitated gently for $5 \mathrm{~min}$ before measuring the optical density at $540 \mathrm{~nm}$ in each well.

\section{Flow cytometric analysis of the cell cycle}

The distinct phases of the cell cycle were classified by DNA staining using the fluorescent dye propidium iodide. These were measured using flow cytometry according to methods described previously (Liu et al, 2002). Data acquisition was performed within $1 \mathrm{~h}$ using a Becton Dickinson FACSCalibur cytometer (BD Biosciences, Oxford, UK), and gating was used to remove doublet artefacts and to discriminate cells from debris. A total of 10000 cells were analysed, and the percentages of cells in G1, S and G2/M phases were determined using the cell cycle analysis program, CellQuest v3.4 (BD Biosciences).

\section{Colony formation in soft agar}

Anchorage-independent growth, a function of transformation, was determined by assaying colony growth in soft agar. Colorectal carcinoma cells were re-suspended in DMEM supplemented with $20 \%(\mathrm{v} / \mathrm{v})$ FBS and containing $0.3 \%$ (w/v) Nobel agar (Sigma Ltd), and a volume of $3 \mathrm{ml}$ was poured onto a 6-well plate containing a pre-solidified agar base layer (0.5\% (w/v) agar and 20\% (v/v) FBS in DMEM - $2 \mathrm{ml}$ ). For drug treatments, cell suspensions were supplemented with thalidomide, lenalidomide or pomalidomide at 1 or $10 \mu \mathrm{M}$. Plates were replenished every 5 days with $500 \mu \mathrm{l}$ basal growth medium (with or without drugs), and colony formation was assessed by light microscopy on day 21 . The sizes of each colony were assessed, and the viabilities of each colony were confirmed by trypan blue dye exclusion.

\section{Cell migration and invasion assays}

Experiments assessing cell migration were performed using a 24-well chemotaxis chamber consisting of a transwell permeable membrane with $3 \mu \mathrm{m}$ pore size. The chemoattractant in the lower compartment of the chamber was basal growth medium $(600 \mu \mathrm{l})$. Colorectal carcinoma cells $\left(1 \times 10^{6} \mathrm{ml}^{-1}\right)$ were re-suspended in DMEM containing $2 \mathrm{mM}$ L-glutamine and $0.1 \%$ bovine serum albumin (BSA). For the treatment groups, cells were co-cultured with each drug at a range of concentrations between 0 and $10 \mu \mathrm{m}$. Cells $(300 \mu \mathrm{l})$ were added to the upper compartment of the chemotaxis chamber, and they were allowed to traverse through the membrane for $16 \mathrm{~h}$ in a humidified atmosphere with $5 \% \mathrm{CO}_{2}$ in air at $37^{\circ} \mathrm{C}$. Cells from either side of the membrane were harvested mechanically and with trypsin, before enumeration by cell counting with trypan blue dye to aid livedead cells discrimination. The percentage of cells traversing the
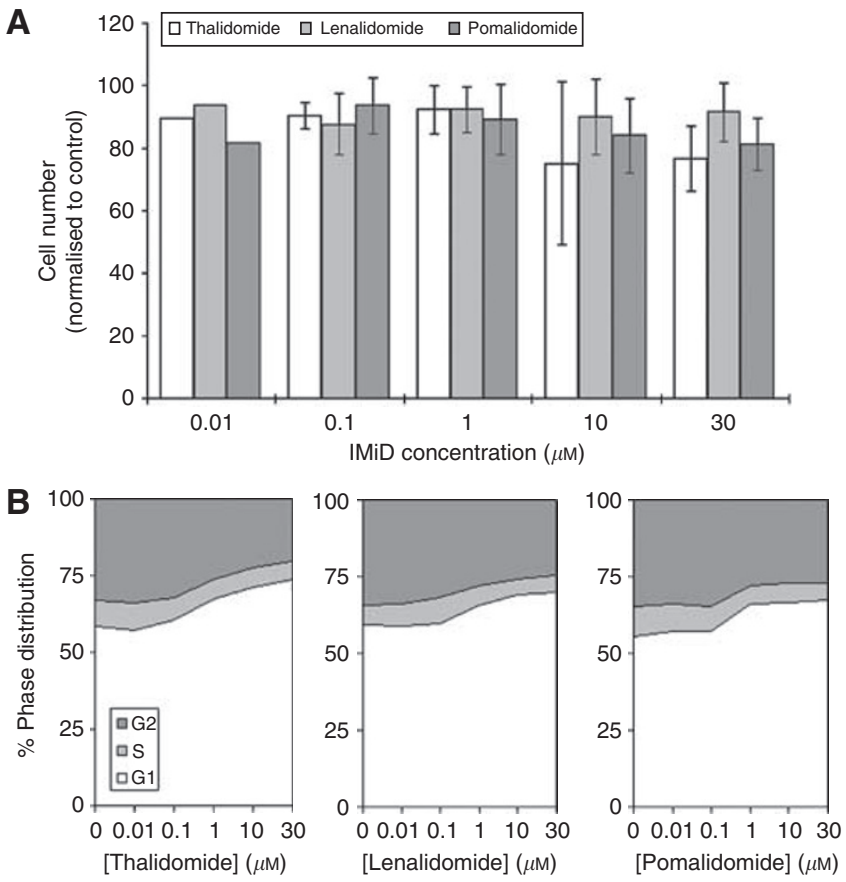

Figure I Effect of IMiDs on cell growth parameters. CT26 cells were cultured continuously with thalidomide, lenalidomide or pomalidomide ${ }_{0}$ $30 \mu \mathrm{M}$ ) for 3 days. Changes in cell numbers were assessed by the MTT assay and are represented by values normalised to control samples with no treatment $(\mathbf{A})$. The effect on cell cycle distribution was also assessed (B). Each data point represents the mean and s.d. (where appropriate) of at least three separate experiments. 
A

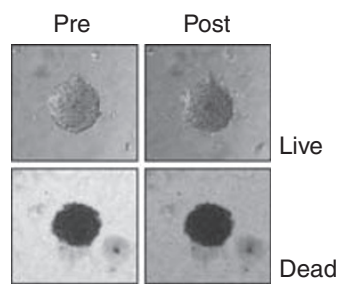

B
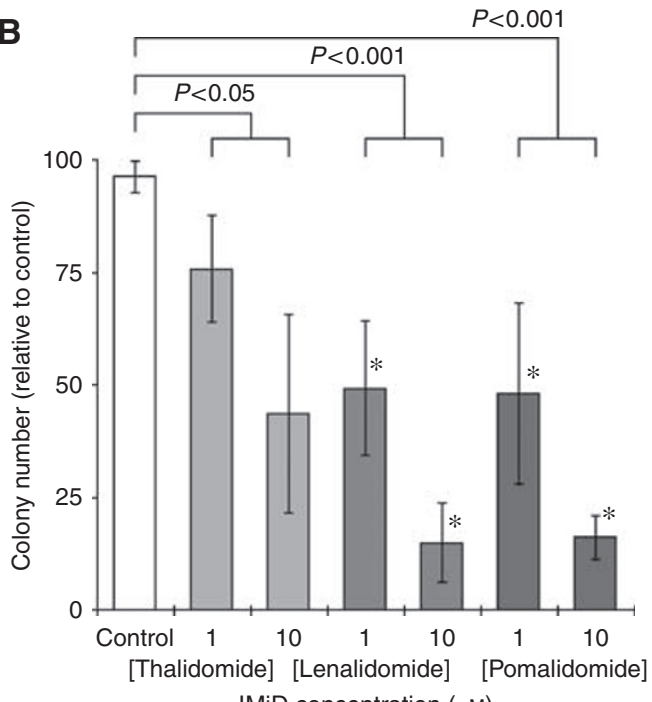

C

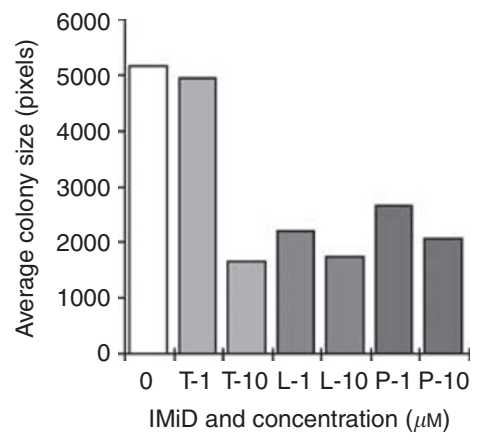

D

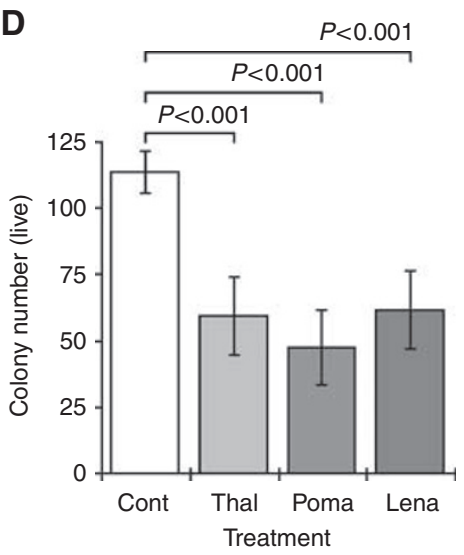

Figure 2 Effect of IMiDs on anchorage-independent growth. CT26 and CMT93 cells were cultured on soft agar with thalidomide, lenalidomide or pomalidomide (I and IO $\mu \mathrm{M}$ ), and colony formation assessed after $2 \mathrm{I}$ days. Non-viable-viable cells were discriminated using trypan blue exclusion (A), and the presence of live colonies in each treatment group was enumerated $(\mathbf{B})$. ${ }^{*} P<0.05$ when compared with thalidomide at the respective concentrations. The representative photographs show a live and a dead colony before and after the addition of trypan blue dye. Each column represents the mean and s.d. of three separate experiments. The average colony size was determined by measuring the area size using art software (C). Significant reductions in the numbers of live colonies derived from CMT93 cells were observed after culture with $10 \mu \mathrm{M}$ of any of the three drugs (D).

permeable membrane into the lower side of the chamber was then calculated.

Cell-invasive capability was assessed using a similar chemotaxis chamber set-up with few modifications. The ability of cells to invade through the basement membrane was assessed by first coating the upper surface of the polycarbonate membrane with $100 \mu \mathrm{g} \mathrm{ml}^{-1}$ of growth factor-reduced Matrigel (BD Biosciences). Matrigel was allowed to set at $37^{\circ} \mathrm{C}$ for $30 \mathrm{~min}$, before adding cells to the upper compartment of the chamber. Cells were allowed to invade through the Matrigel and permeable membrane, before being harvested using the same methods described above. Cell recovery from the Matrigel layer was enhanced using the Cell Recovery Solution (BD Biosciences), and the percentage of cells in the lower compartment $v s$ the upper chamber was calculated.

\section{Immunoblotting analysis}

Cells were harvested and total cellular protein was solubilised in lysis buffer (New England Biolabs, Hitchin, UK) and resolved by Tris-glycine electrophoresis using a 4-20\% gradient gel according to the method of Laemmli (1970) After transferring proteins to nitrocellulose membranes $(0.45 \mu \mathrm{m})$, blocking was performed in $5 \%(\mathrm{w} / \mathrm{v})$ non-fat milk in TTBS $(0.1 \%(\mathrm{v} / \mathrm{v})$ Tween-20 in TBS (100 mm Tris, $150 \mathrm{~mm} \mathrm{NaCl}, \mathrm{pH}$ 7.6)). Primary antibody probing was performed with anti-phosphoAKT ${ }^{\text {ser473 }}$, anti-AKT, antiphosphoMAPK ${ }^{\text {erk1/2}}$, anti-MAPK, anti-VEGF-R1 (1:500 - Abcam PLC, Cambridge, UK), anti-cadherin and anti-MMP-9. All primary antibodies were obtained from New England Biolabs and used at a dilution of $1: 1000$, unless stated otherwise. Anti-GAPDH was used as a loading control (1:2000 - New England Biolabs). After three washing steps in TTBS, horseradish peroxidase-conjugated antispecies $\mathrm{IgG}_{1}$ was used as the secondary antibody (Amersham Biosciences Ltd, Little Chalfont, UK). Bands were visualised using the ECL-plus detection system (Amersham Biosciences Ltd).

\section{Measurement of cytokine production}

CT26 cells $\left(1 \times 10^{5}\right.$ cells) were cultured for 3 days in 6 -well plates in the basal medium supplemented with thalidomide, lenalidomide or pomalidomide at concentrations between 0.01 and $30 \mu \mathrm{M}$. After incubation, the media were removed, debris removed by micro-centrifugation at $13000 \mathrm{~g}$ for $10 \mathrm{~min}$ and stored at $-80^{\circ} \mathrm{C}$ for further analysis. Changes in the expressions of a collection of metastatic-related activating and inhibiting proteins were initially screened and assessed using the TranSignal Mouse Angiogenesis Antibody Array (Panomics Inc., Redwood City, CA, USA) according to the manufacturer's protocols. Furthermore, the levels of VEGF (Peprotech EC Ltd, London, UK), IP10 and TIMP1 (both from Bender MedSystems GmbH, Vienna, Austria) were assayed using ELISA kits according to the manufacturer's instructions.

\section{In vivo murine experimental metastasis model}

Exponentially growing CRC cells were harvested, washed and resuspended in PBS at a concentration of $1.3 \times 10^{5}$ per ml. Only cells 

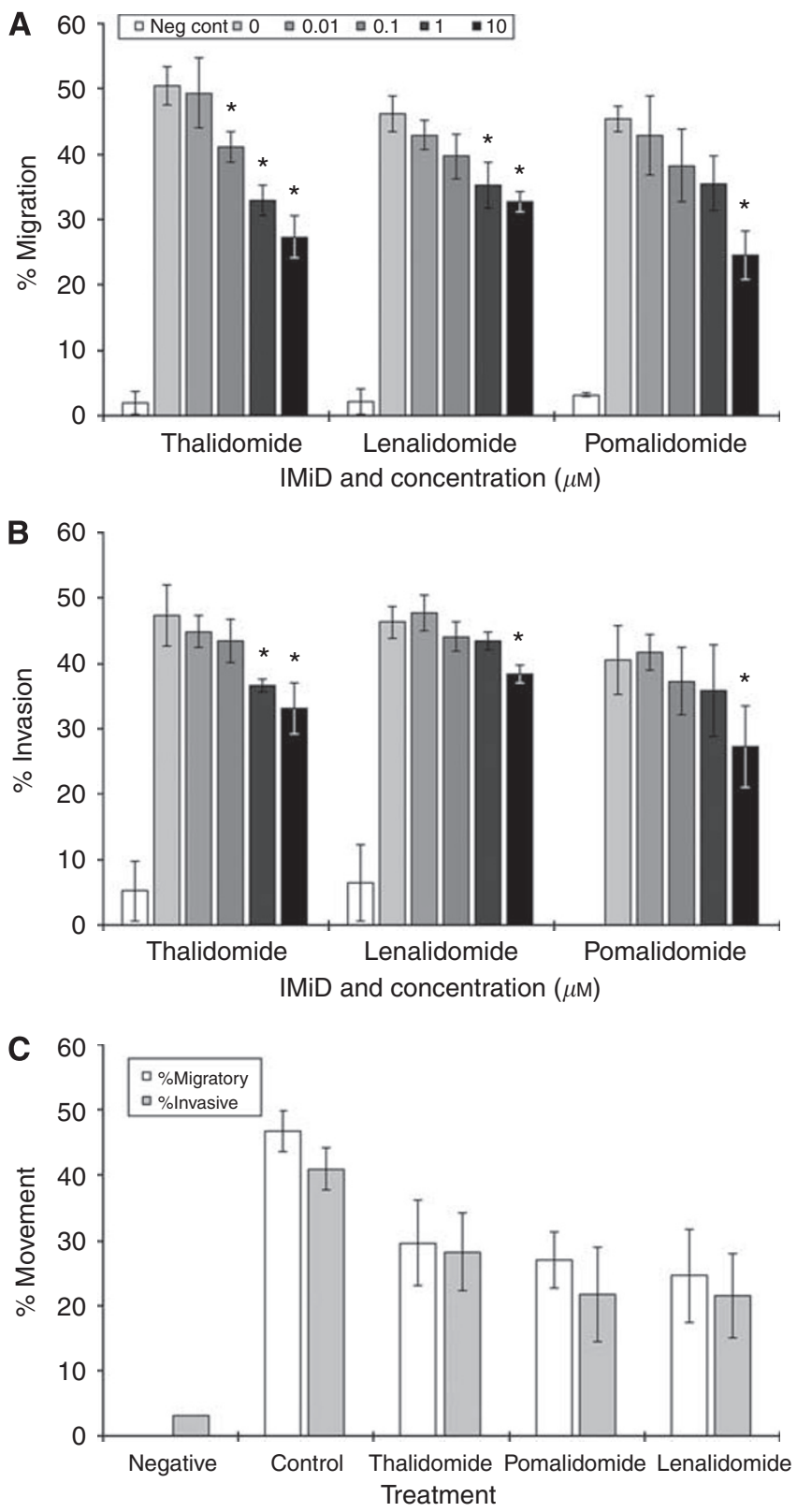

Figure 3 Effect of IMiDs on the migration and invasion of cells. CT26 (A, B) and CMT93 (C) cells were re-suspended in FBS-free growth medium in the presence of absence of thalidomide, lenalidomide or pomalidomide $(0-10 \mu \mathrm{M})$, and loaded into a chemotaxis chamber. The percentage of migratory and invasive cells was established by counting the cells in either compartment of a chemotaxis chamber after 16 h. Each column represents the mean and s.d. of at least three separate experiments. The effect of only $10 \mu \mathrm{M}$ of each drug was assessed in CMT93 (panel C).

with a viability of $>90 \%$, as established by trypan blue dye exclusion analysis, were used. Mice (BALB/c for CT26 and C57BL/6 for CMT93) were anaesthetised with isoflurane and inoculated into the tail vein with $150 \mu \mathrm{l}$ of cells. Thalidomide, lenalidomide or pomalidomide $\left(50 \mathrm{mg} \mathrm{kg}^{-1}\right)$ was administered daily by intraperitoneal injection. Mice were killed 14 days after tumour cell inoculation. For enumeration of pulmonary metastases of CRC cells, the lungs were perfused intra-tracheally with a $15 \%$ solution of Indian ink, resected and stabilised in Fekete's solution $(70 \%$ $(\mathrm{v} / \mathrm{v})$ ethanol, $5 \%(\mathrm{v} / \mathrm{v})$ formaldehyde and $750 \mathrm{~mm}$ glacial acetic acid in water). Metastases that appeared as white nodules on the surface of the lungs were counted independently by two operators.

A parallel experiment was also performed with CT26 cells in $\mathrm{BALB} / \mathrm{c}$ mice using the slightly more active of the drugs. CT26 cells $\left(1 \times 10^{5}\right.$ cell per $\left.\mathrm{ml}\right)$ were pre-treated in vitro with $10 \mu \mathrm{M}$ lenalidomide for 3 days, before inoculation into mice. Mice $(n=10)$ were then treated with lenalidomide or vehicle $(0.5 \%(\mathrm{v} / \mathrm{v})$ DMSO in PBS) for 14 days, before assessment of metastatic lesions as described above.

\section{Immunohistochemistry of the lungs from $B A L B / c$ mice}

The lungs from BALB/c mice inoculated with CT26 cells and treated with thalidomide, pomalidomide or lenalidomide were fixed in an embedding compound and frozen in liquid nitrogen. Cryosections $(6 \mu \mathrm{m})$ were fixed onto positively charged slides in ice-cold acetone for routine haematoxylin and eosin staining (Department of Pathology, St George's Hospital, London, UK) and for assessment of VEGF-R1 levels. Slides were blocked in 5\% BSA $(w / v)$ in PBS before incubation at room temperature with antiVEGF-R1 (1:50; Abcam PLC) for $3 \mathrm{~h}$. After the three 5-min washing steps in PBS, Alexa Fluor 568-conjugated secondary antibody (1:50; Invitrogen Ltd, Paisley, UK) was applied to the slides and incubated overnight at $4{ }^{\circ} \mathrm{C}$ in darkness. The slides were washed three times in PBS and coverslips applied using mounting media containing 4',6-diamidino-2-phenylindole (Vector Laboratories Inc., Burlingame, CA, USA). Sections were imaged using an Olympus CKX-41 inverted microscope (Olympus, East Grinstead, UK), and the VEGF-R1 expression was assessed independently by two operators.

\section{RESULTS}

\section{Thalidomide/IMiDs do not affect the proliferation of CT26 cells}

The effect of IMiDs on cell proliferation was assayed by MTT analysis, and the concentration ranges were clinically achievable and tolerated. Results showed that thalidomide, lenalidomide and pomalidomide at concentrations ranging between 1 and $10 \mu \mathrm{m}$ had no significant effects on cell number and viability (Figure 1A). Flow cytometric analysis indicated no changes in the sub-G1 phase of the cell cycle that are suggestive of apoptosis, but highlighted a possible arrest at the G1 phase of the cell cycle and concomitant fall in the G2/M phase (Figure 1B).

\section{Thalidomide/IMiDs reduce the clonogenic potential of CRC cells}

All the controls of CT26 and CMT93 cells that were treated with DMSO showed significant growth in soft agar, with an average live colony counts of $127 \pm 43$ (mean \pm s.d.) and $114 \pm 8.1$, respectively, on day 21. In CT26 experiments, the percentage of live colonies as assessed by trypan blue analysis was $96 \pm 3.5 \%$ (Figure 2A). The numbers of live colonies was significantly reduced after culturing with IMiDs $(P<0.001)$ (Figure $2 \mathrm{~B})$. Equally, the average sizes of the colonies in the treated cultures were reduced (Figure 2C). Significant reductions in the numbers of live colonies were also observed in CMT93 cells cultured with the drugs (Figure 2D).

\section{Thalidomide/IMiDs reduce the FBS-mediated migration of CRC cells}

The effect of IMiDs on the metastatic capabilities of CT26 and CMT93 cells was also examined by assessing the ability of cells to migrate across a permeable membrane towards $10 \%$ FBS in a $16 \mathrm{~h}$ period. (Figure $3 \mathrm{~A}$ and $\mathrm{C}$ ). The IMiDs were used at concentrations that were not cytotoxic at this short period of time, and the 
A Thalidomide Pomalidomide Lenalidomide
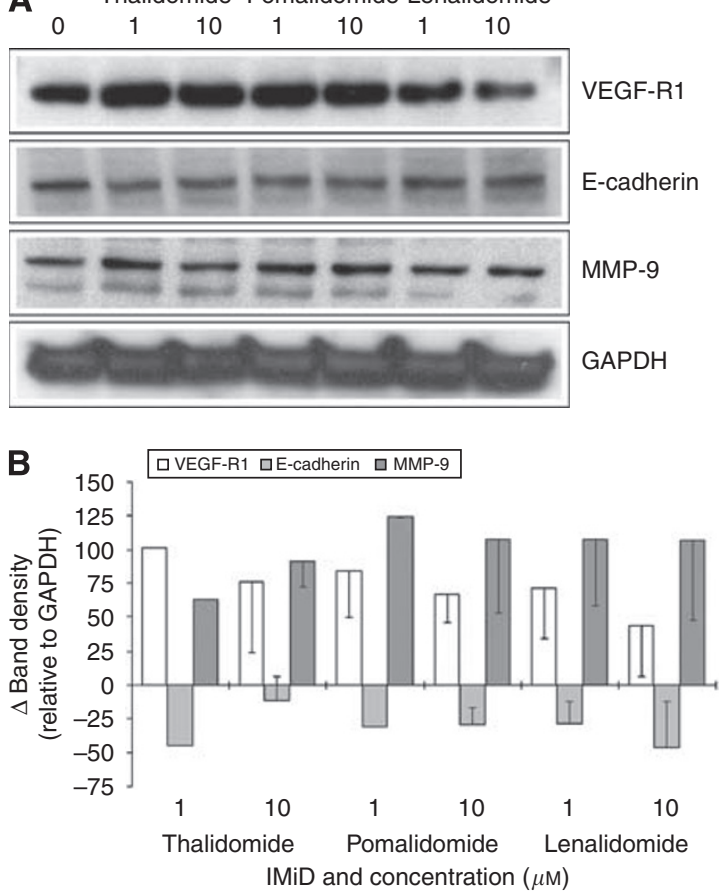

C

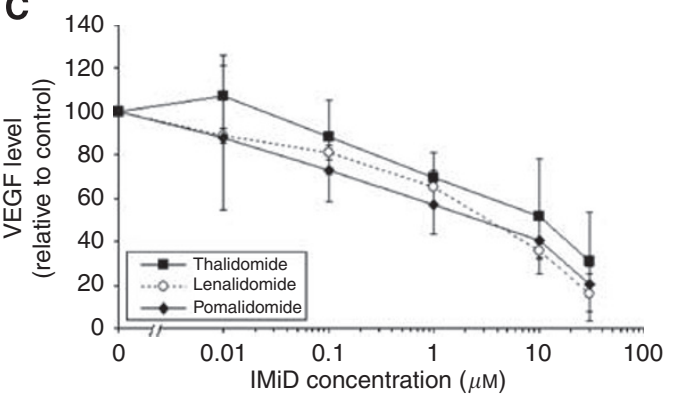

D tha lena poma

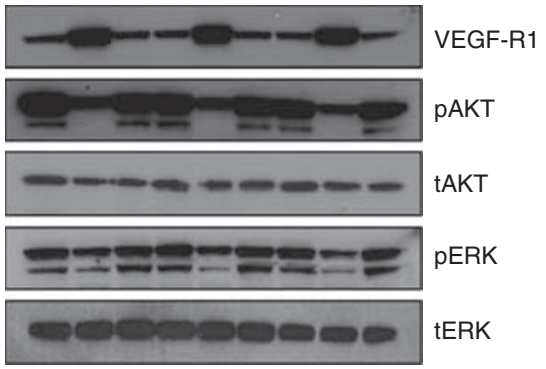

Figure 4 Effect of the IMiDs on the expression of metastatic markers and intracellular signalling proteins. CT26 cells were cultured with thalidomide (tha), lenalidomide (lena) or pomalidomide (poma) (0-30 $\mu \mathrm{M}$ ) for 3 days. The expressions of VEGF-RI, E-cadherin and MMP-9 were assessed by immunoblot analyses. Representative blots are shown $(\mathbf{A})$, and densitometric analysis using GAPDH as the loading control was carried out (B). The levels of VEGF within the supernatant were also assessed by ELISA $(\mathbf{C})$. The expressions of key signalling proteins after treatment ( $10 \mu \mathrm{M}$ - designated by a ' $T$ ') were assessed and compared with controls with no treatment ('C') and those with equal DMSO solvent exposure ('D') (D). Each data point is the mean and s.d. of three separate blots.

viability of cells in both compartments of the chemotaxis chambers was $>90 \%$. Migration in control wells, in which FBS was replaced with $0.1 \%$ BSA was minimal (\%migration $<2.4 \pm 1.5 \%$ ). There was a concentration-dependent reduction in the migration of cells when cultured with IMiDs, which reach significance at the higher doses $(P<0.001)$. In addition, there was no significant difference in the migratory capacity between the drugs tested.

\section{Thalidomide/IMiDs reduce the invasion of CRC cells through Matrigel}

The movement of CT26 and CMT93 cells through a layer of extracellular matrix (Matrigel) was studied in the same chemotaxis chambers used in the migration assays. The ability of cells to invade through the layer and into $10 \%$ FBS was established by counting the number of cells located on both sides of the membrane. Cells were harvested from Matrigel using a proprietary cell recovery solution that significantly reduced cell viability; hence the percentage of invasive cells was calculated using total cell numbers rather than viable cell numbers. Results showed that IMiDs substantially reduced the percentage of invading cells (Figure $3 \mathrm{~B}$ and $\mathrm{C}$ ).

\section{Thalidomide/IMiDs alter the expression of metastatic markers}

To investigate whether the changes in the macroscopic metastatic sub-systems were associated with changes in intracellular biomarkers of metastasis, whole cell lysates obtained from CT26 cells cultured with IMiDs were analysed by immunoblotting. Results showed that there was no significant effect to E-cadherin; however, there were increases in the expressions of tumour VEGF-R1 and MMP-9 (Figure 4A). Densitometry analyses of the autoradiograms showed these changes to be statistically significant compared with control samples treated with DMSO alone (Figure 4B).

\section{Thalidomide/IMiDs reduce VEGF production by CT26 cells}

In an attempt to establish the cytokines and growth factors in the supernatant derived from CT26 cells, we used a proprietary sandwich ELISA kit to assess the proteins present in the medium. The signals for all the proteins on the ELISA array when assaying the basal medium (DMEM $+10 \%$ FBS) were below the threshold of detection. However, a number of proteins present in the conditioned medium were flagged, of which, VEGF, IP10 and TIMP1 were consistently seen (Figure 5A and B). We next assessed the effects of the drugs on the capacity of CT26 cells to secrete these cytokines using ELISA plates. Results showed that the drugs did not affect the levels of IP10 and TIMP1; however, VEGF was significantly reduced by treatment (Figure $5 \mathrm{C}$ ). Furthermore, the effect on VEGF was dose-dependent (Figure 4C).

\section{Thalidomide/IMiDs alter levels of proteins associated with} intracellular signalling

To investigate whether intracellular signalling cascades were affected by treatment with IMiDs, whole cell lysates from CT26 cells cultured with $10 \mu \mathrm{M}$ of thalidomide, lenalidomide or pomalidomide for 3 days were analysed by immunoblotting. Results showed significant reductions in pAKT and pERK accompanied by an increase in VEGF-R1 levels (Figure 4D).

\section{Thalidomide/IMiDs inhibit pulmonary metastasis in vivo}

The propensity of CRC cells to spontaneously seed into and grow within the lungs of mice after tumour cell injection into the tail 
A
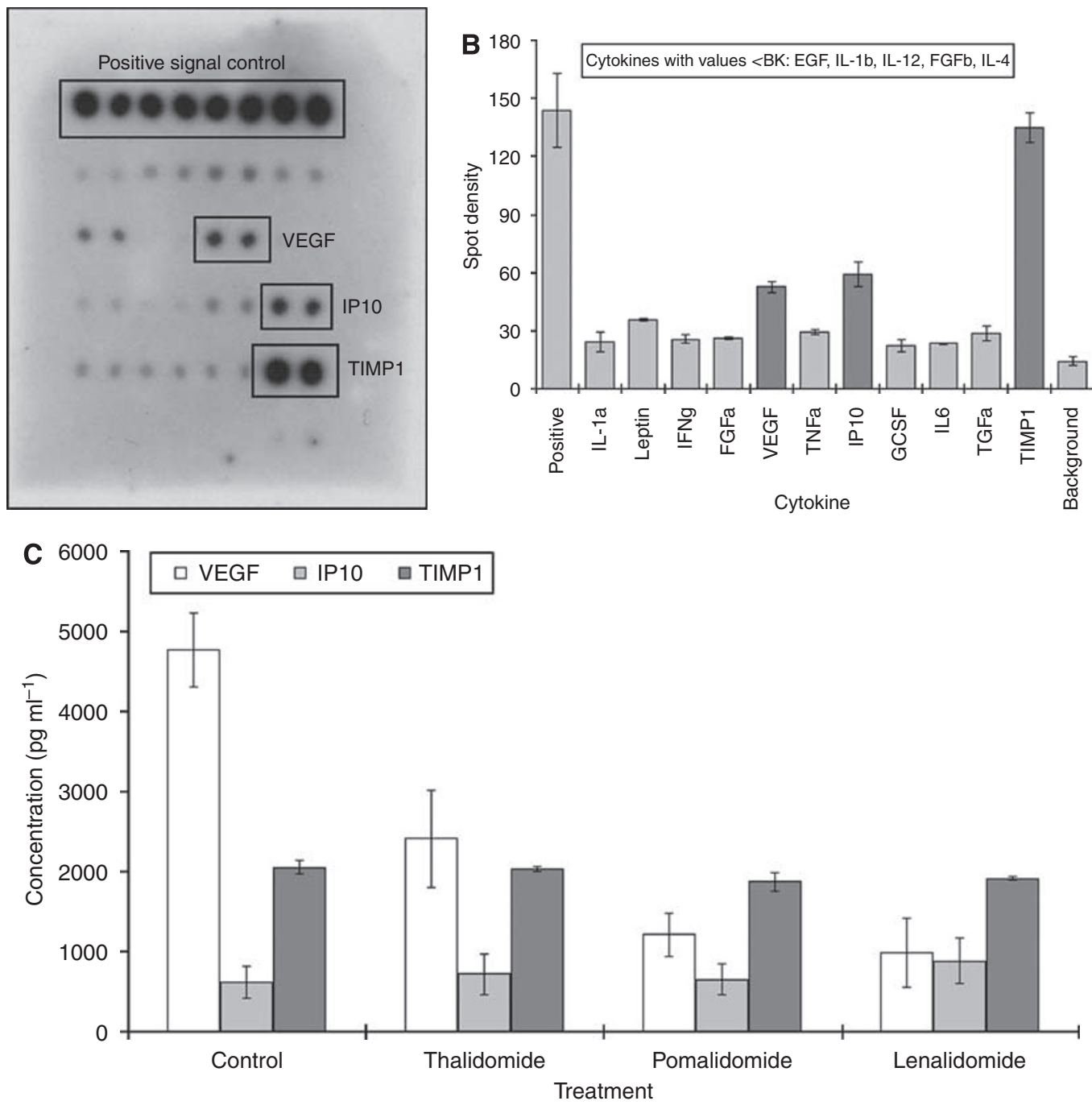

Figure 5 Effect of the IMiDs on the expression of angiogenic and metastatic markers. CT26 cells were cultured with the drugs for 3 days, and the growth medium was harvested. These tumour-conditioned media were subjected to assessment of proteins associated with angiogenesis and metastasis. Assessing conditioned media derived from untreated tumours indicated that some cytokines were below the magnitude background (BK) (A. B). Three cytokines, VEGF, IPIO and TIMPI, that were registered as consistently present in the media were assessed after treatment and results show that only VEGF was affected (C).

vein was used as the in vivo model of metastasis. The method is widely used, and easily defines metastatic potential - that is the ability of tumour cells to seed, evade host immuno-surveillance and to interact with the microenvironment by receiving growth and survival signals from it (Khanna and Hunter, 2005). Results showed that metastasis into the lung was significantly decreased in $\mathrm{BALB} / \mathrm{c}$ mice treated with IMiDs compared with that in untreated mice $(P<0.001$ in all cases) (Figure $6 \mathrm{~A})$. As an example, the average number of pulmonary nodules from 28 untreated BALB/c mice was 95 , whereas the average number in 15 mice treated daily with $50 \mathrm{mg} \mathrm{kg}^{-1}$ of thalidomide was 17 . These data were recapitulated in C57BL/6 mice injected with the CMT93 cell line, with significant reductions in the number of pulmonary nodules after treatment with thalidomide, lenalidomide or pomalidomide (Figure 6B).

In addition, immunohistochemistry analyses of the lungs resected from $B A L B / c$ mice showed an absence of tumourinfiltrating lymphocytes into the pulmonary cellular aggregates (Figure 7). These analyses also recapitulated the increased expression of VEGF-R1 after treatment with IMiDs compared with samples derived from the untreated control group (Figure 7).

\section{Pre-treatment with lenalidomide is sufficient to reduce metastasis in vivo}

CT26 cells were pre-cultured with lenalidomide for 3 days before introduction into the mice as an attempt to understand the effect of the drugs on metastatic capability. Pre-treatment did not result in significant changes in cell number and viability. Results showed that metastasis was reduced in the untreated mice inoculated with CT26 cells pre-treated with lenalidomide (number of metastatic nodules: $19 \pm 3.7$ vs $43 \pm 4.6$ in control mice inoculated with untreated cells) (Figure 6C).

\section{DISCUSSION}

This study was undertaken as part of our larger remit to understand the mechanism of action of the thalidomide-related IMiDs in their inhibition of tumour progression. To this end, we specifically investigated the effects of thalidomide, lenalidomide and pomalidomide on the metastatic capability of a colon tumour cell in a number of in vitro and in vivo models. Using in vitro 

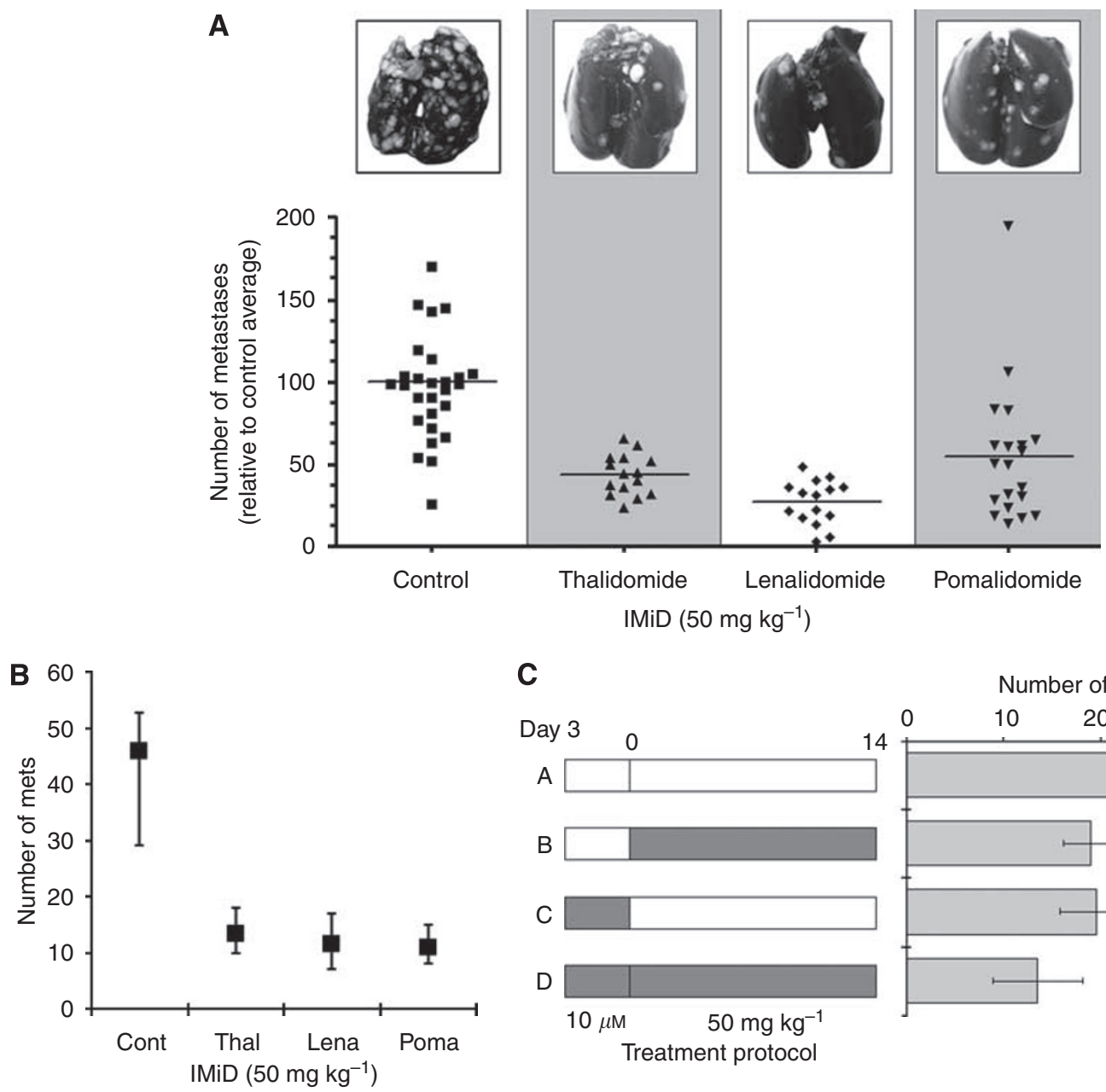

C

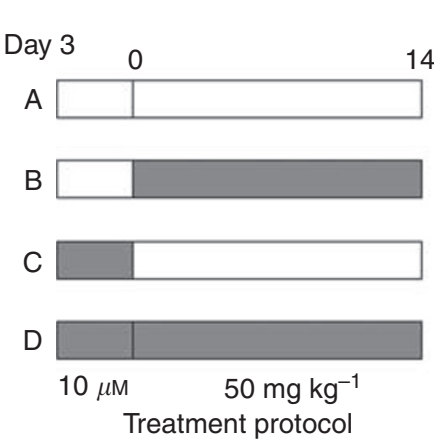

Number of pulmonary nodules

$\begin{array}{llllll}0 & 10 & 20 & 30 & 40 & 50\end{array}$

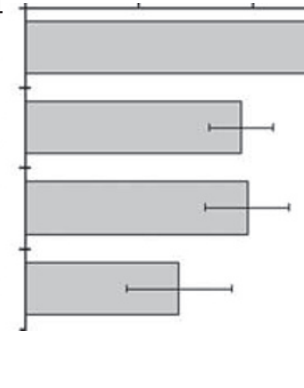

Figure 6 Effect of the IMiDs on pulmonary metastases. CT26 cells were injected into the tail vein of BALB/c mice. The effect of thalidomide, lenalidomide and pomalidomide administered daily IP on pulmonary metastases was assessed on day I4 (A). There were significantly fewer metastatic nodules in the lungs resected from treated animals $(P<0.00$ I vs controls). Representative lungs are also shown. Similar reductions in metastatic nodules of $C M T 93$ were observed in mice treated with the drugs $(\mathbf{B})$. Each data point represents the means and ranges of five animals. The effect on metastasis of pre-treating CT26 cells for 3 days with $10 \mu \mathrm{m}$ lenalidomide was also studied $(\mathbf{C})$, where the shaded bars indicate treatment with lenalidomide. Pre-treatment (treatment protocol C) resulted in fewer nodules.

models and the drugs at physiologically achievable and clinically relevant concentrations (Galustian et al, 2009; Liu et al, 2009b), we could assess the effects on metastasis that were independent of an immune response. In addition, the colorectal CT26 cell line was used exclusively as it was syngeneic to the $\mathrm{BALB} / \mathrm{c}$ mouse, which would allow in vivo and in vitro mechanistic studies to be related to each other. In summary, we confirmed that these agents significantly reduced metastasis capability directly, which was independent of a specific cytotoxic effect. Moreover, we showed that the inhibition was associated with, and mediated in part by, alterations to intracellular signalling.

The clinical value of thalidomide against solid tumours may lie in its immunomodulatory, anti-angiogenic and anti-metastatic properties. The immunomodulatory feature is believed to be a crucial determinant of clinical success and as such, analogues of thalidomide and those related to it have shown greatly increased potency for costimulation of T-cell and NK cells (Corral et al, 1999; Haslett et al, 2003; Aragon-Ching et al, 2007; Wu et al, 2008). These drugs have impressive activity in both haematological cancers (Galustian et al, 2004); however, it is not known whether the activity of solid tumours will be as strong. In haematological cancers, direct anti-survival and pro-apoptotic effects have been described for thalidomide/IMiDs that are independent of an immune response, which may be the underlying reason for therapeutic activity in neoplasia (Mitsiades et al, 2002; Liu et al, 2004). It is important to understand that the induction of tumour cytotoxicity can also be a result of an enhanced immunological responses caused by IMiDs. The increased proliferation of a number of immune cell groups, including CD4-positive and CD8-positive cells in addition to the initiation of dendritic cell function, can lead to the activation of natural killer cells that drive cytophagy and cytolysis (Davies et al, 2001; Hayashi et al, 2005; Wu et al, 2008).

One in vitro characteristic of tumour cells, which distinguishes them from normal non-tumourigenic cells, is their ability to grow competently in soft agar (Freedman and Shin, 1974; Shin et al, 1975). This hallmark of phenotypic transformation is observed in the majority of cancers, and occurs through the ability of the cell to gradually escape their dependence on growth regulatory mechanisms. Anchorage-independent growth has been correlated with the in vivo development of murine tumour cells (Cifone and Fidler, 1980) and with the propensity of tumour cells to develop metastasis in vivo. Our results indicated that single-cell suspension of untreated CT26 cells successfully developed into relatively large colonies of viable cells, whereas those cultured with IMiDs resulted in fewer and smaller-sized colonies, a large number of which were composed of non-viable cells. It has been shown that 

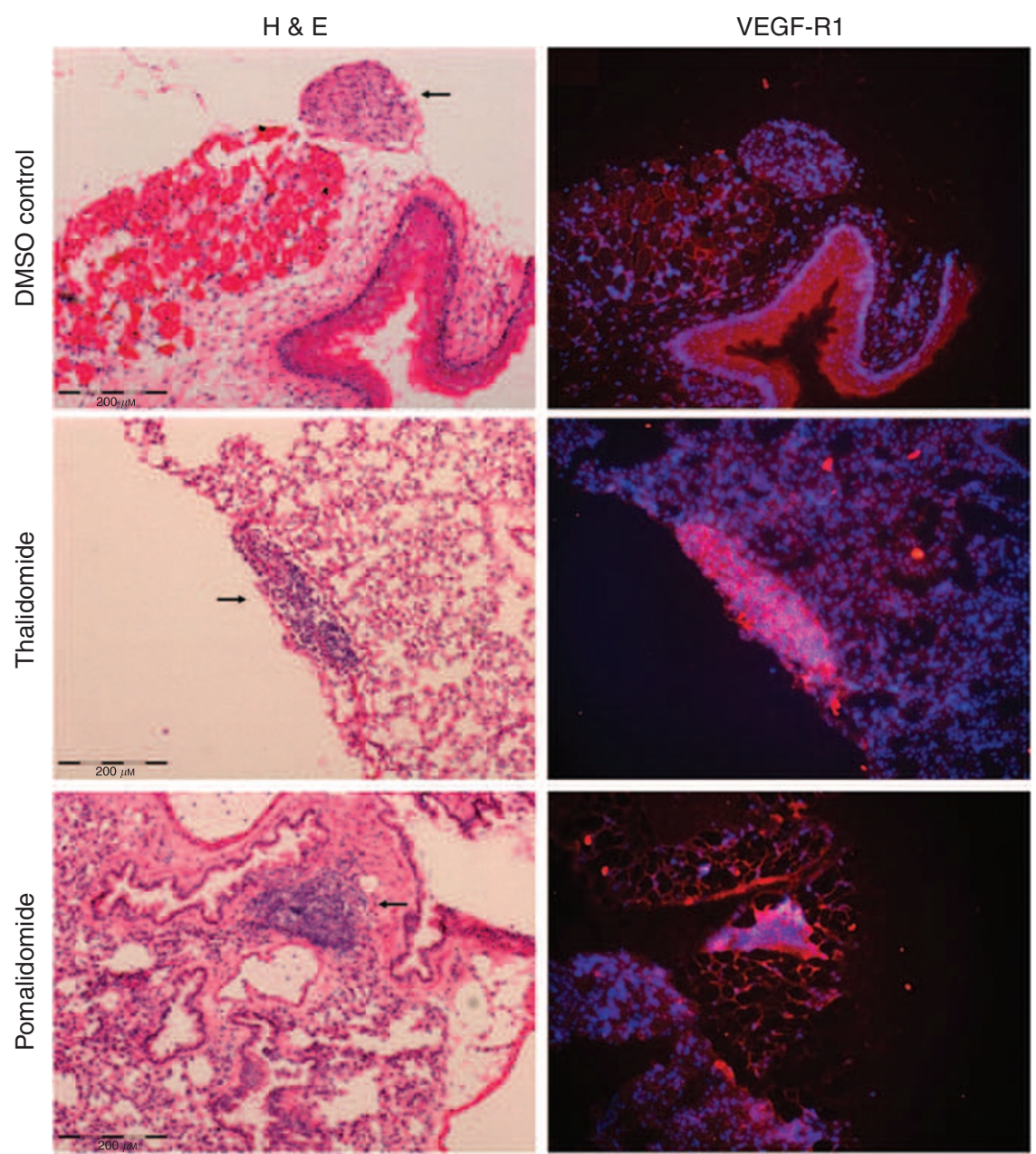

Figure 7 Effect of thalidomide and pomalidomide on VEGF-RI expression in pulmonary metastases. Immunohistochemistry was performed on lung sections derived from mice treated with DMSO controls, thalidomide or pomalidomide. Metastases were identified as cellular aggregates (arrow) by H\&E staining. There was an absence of infiltrating lymphocytes into these masses. VEGF-RI expression was assessed using Alexa Fluor 568 (red) and cell nuclei counterstained with DAPI (blue), and shown to be low in the DMSO-treated group, but increased in thalidomide and pomalidomide sections. No cellular aggregates were observed in the sections from the lenalidomide-treated group.

the gradual loss of anchorage-independent growth capability results in smaller colonies, indicating a loss of transformed phenotype (Gu et al, 2006). Supplementary to this, the presence of non-viable cells within these colonies suggests a cytotoxic effect (Alley et al, 1982); however, the concentrations of IMiDs used in the soft agar assay were not cytotoxic (Figure 1). Parenthetically, these concentrations were used in all the in vitro studies as they were clinically relevant and achievable in patients $(\mathrm{Wu}$ and Scheffler, 2004). These data suggested that the ability to initiate colony development independently of anchorage was not affected, whereas the ability to maintain growth of these colonies was compromised.

In support of the clonogenecity data, we next examined the effect of IMiDs on tumour cell motility. There is a deficit of information in this area, and although there are limited reports detailing reduced migratory characteristics in endothelial cells, there are very little data reporting these effects in tumour cells (Dredge et al, 2005; Komorowski et al, 2006). In accordance with the findings of the soft agar study, migration and invasion capacity was significantly hampered by IMiD treatment. Furthermore, the reduction in motility was not a consequence of increased cell death as the duration of exposure to drugs was $16 \mathrm{~h}$ and the cell viabilities in either compartment of the chemotaxis chambers were $>90 \%$. Taken together, IMiDs interfere with three key stages of metastasis - namely transformation, migration and invasion - and thus can reduce the overall metastatic capability of tumour cells. Reassuringly, the frequency of pulmonary tumours in a murine experimental metastasis model was also reduced after treatment with IMiDs, which supported the in vitro arm of our study. Furthermore, the reduction in pulmonary metastatic nodules in mice inoculated with tumour cells pre-treated with IMiDs, allied to the absence of lymphocyte infiltration into pulmonary cell plaques, suggested that this antimetastatic effect of the drugs may have been independent of an immune response.

Tumourigenicity is an iterative process that requires interactions between tumour and the host microenvironment. Paracrine communications between tumour cells and endothelial cells exist to initiate, propagate and support tumour cells, and involve cross-talk between a number of chemokines, such as VEGF, IL-8 and IL-2 and their receptors (De Luca et al, 2008). In particular, the VEGF-R family, including VEGF-R1 and VEGF-R2, is known to be a crucial mediator of metastasis in vivo (Shibuya, 2001). These in turn, impact intracellular signalling cascades, such as MAPK and PI3-K (Reddy et al, 2003; Chan, 2004). Indeed, establishing the degree of metastasis and neovascularisation by measuring biomarkers of endothelial cell function and their interactions with tumour cells are prognostic indicators in 
neoplasia (Mustonen and Alitalo, 1995; Dales et al, 2004; Saad et al, 2004). Of the small group of markers studied, there was a significant increase in VEGF-R1 in CT26 cells after treatment with any of the IMiDs. This at first appeared to be counterpredicted, as these proteins are normally associated with promoting metastasis (Mustonen and Alitalo, 1995; Bergers et al, 2000). However, VEGF-R1 has a unique mode of action in that it has a relatively weak kinase activity even though it has a greater ligand binding affinity (Mustonen and Alitalo, 1995), and hence it functions primarily as a decoy receptor and ultimately sequesters free VEGF. Ultimately, the incidence of VEGF binding the functional subtype VEGF-R2 is reduced, which results in reduced metastatic capacity (Beck and D'Amore, 1997; Yancopoulos et al, 2000). Furthermore, as MMP-9 is induced by VEGF-R1, any increases in the latter would cause an increase in the former (Hiratsuka et al, 2002), which would explain our observations. Consequently, we explored the VEGF-R1 function further by measuring free VEGF levels and the status of signalling cascades downstream of this receptor kinase. These were reduced in all the treatment groups in which an increase in the decoy VEGF-R1 was observed. Parenthetically, as these drugs disrupt cytokine production at an mRNA level, changes in their expressions and function maybe due to post-translational processes (Liu et al, 2009b), which may fortify their actions.

In summary, these data reaffirm the complexity of the data surrounding the mechanism(s) of action(s) for the IMiDs, high-

\section{REFERENCES}

Alley MC, Uhl CB, Lieber MM (1982) Improved detection of drug cytotoxicity in the soft agar colony formation assay through use of a metabolizable tetrazolium salt. Life Sci 31: 3071-3078

Aragon-Ching JB, Li H, Gardner ER, Figg WD (2007) Thalidomide analogues as anticancer drugs. Recent Patents Anticancer Drug Discov 2: $167-174$

Bartlett JB, Dredge K, Dalgleish AG (2004) The evolution of thalidomide and its IMiD derivatives as anticancer agents. Nat Rev Cancer 4: $314-322$

Bartlett JB, Tozer A, Stirling D, Zeldis JB (2005) Recent clinical studies of the immunomodulatory drug (IMiD) lenalidomide. $\mathrm{Br} J$ Cancer 93: $613-619$

Beck Jr L, D’Amore PA (1997) Vascular development: cellular and molecular regulation. FASEB J 11: 365-373

Bergers G, Brekken R, McMahon G, Vu TH, Itoh T, Tamaki K, Tanzawa K, Thorpe P, Itohara S, Werb Z, Hanahan D (2000) Matrix metalloproteinase- 9 triggers the angiogenic switch during carcinogenesis. Nat Cell Biol 2: $737-744$

Blansfield JA, Caragacianu D, Alexander III HR, Tangrea MA, Morita SY, Lorang D, Schafer P, Muller G, Stirling D, Royal RE, Libutti SK (2008) Combining agents that target the tumor microenvironment improves the efficacy of anticancer therapy. Clin Cancer Res 14: 270-280

Chan S (2004) Targeting the mammalian target of rapamycin (mTOR): a new approach to treating cancer. Br J Cancer 91: $1420-1424$

Chanan-Khan AA, Cheson BD (2008) Lenalidomide for the treatment of B-Cell malignancies. J Clin Oncol 26: 1544-1552

Cifone MA, Fidler IJ (1980) Correlation of patterns of anchorageindependent growth with in vivo behavior of cells from a murine fibrosarcoma. Proc Natl Acad Sci 77: 1039-1043

Corral LG, Haslett PA, Muller GW, Chen R, Wong LM, Ocampo CJ, Patterson RT, Stirling DI, Kaplan G (1999) Differential cytokine modulation and $\mathrm{T}$ cell activation by two distinct classes of thalidomide analogues that are potent inhibitors of TNF-alpha. J Immunol 163: $380-386$

Dales JP, Garcia S, Carpentier S, Andrac L, Ramuz O, Lavaut MN, Allasia C, Bonnier P, Taranger-Charpin C (2004) Prediction of metastasis risk (11 year follow-up) using VEGF-R1, VEGF-R2, Tie-2/ Tek and CD105 expression in breast cancer $(\mathrm{n}=905)$. Br J Cancer 90: $1216-1221$

D’Amato RJ, Loughnan MS, Flynn E, Folkman J (1994) Thalidomide is an inhibitor of angiogenesis. Proc Natl Acad Sci 91: 4082-4085 lighting direct on-tumour effects in addition to the more classic immunomodulatory effects of this class of drug. As part of our continuing studies, we have clearly shown that the drugs significantly reduce the clonogenic and metastatic capacity of tumour cells in vitro. Allied to these findings, impressive reductions in the frequency of pulmonary metastases were observed in mice that appeared to be achieved independently of immune function. In addition, we have also clearly shown a reduction in cell signalling in tumour cells. Taken together, these drugs appear to reduce reverse tumourigenicity and reduce metastasis. Finally, considering the impact on VEGF-R signalling, it would be prudent to investigate the benefit of combining these agents with inhibitors of receptor tyrosine kinases; our models predicts possible enhanced effects. This is an area that we are currently pursuing, and indeed, highlights another useful facet to an already growing list of mechanisms of actions for this class of IMiDs.

\section{ACKNOWLEDGEMENTS}

The authors would like to thank the staff at the Biological Research Facility of St George's, University of London, particularly Mr Will Murphy, for technical assistance with the animal studies. The authors also thank Ms Jamuna Jeevahan and Ms Anita Patel for their help and advice with immunohistochemistry.

Davies FE, Raje N, Hideshima T, Lentzsch S, Young G, Tai YT, Lin B, Podar K, Gupta D, Chauhan D, Treon SP, Richardson PG, Schlossman RL, Morgan GJ, Muller GW, Stirling DI, Anderson KC (2001) Thalidomide and immunomodulatory derivatives augment natural killer cell cytotoxicity in multiple myeloma. Blood 98: 210-216

De Luca A, Carotenuto A, Rachiglio A, Gallo M, Maiello MR, Aldinucci D, Pinto A, Normanno N (2008) The role of the EGFR signaling in tumor microenvironment. J Cell Physiol 214: 559-567

Dimopoulos M, Spencer A, Attal M, Prince HM, Harousseau JL, Dmoszynska A, San Miguel J, Hellmann A, Facon T, Foà R, Corso A, Masliak Z, Olesnyckyj M, Yu Z, Patin J, Zeldis JB, Knight RD, Multiple Myeloma (010) Study Investigators (2007) Lenalidomide plus dexamethasone for relapsed or refractory multiple myeloma. $N$ Engl J Med 357: $2123-2132$

Dredge K, Horsfall R, Robinson SP, Zhang LH, Lu L, Tang Y, Shirley MA, Muller G, Schafer P, Stirling D, Dalgleish AG, Bartlett JB (2005) Orally administered lenalidomide (CC-5013) is anti-angiogenic in vivo and inhibits endothelial cell migration and Akt phosphorylation in vitro. Microvasc Res 69: $56-63$

Dredge K, Marriott JB, Macdonald CD, Man HW, Chen R, Muller GW, Stirling D, Dalgleish AG (2002) Novel thalidomide analogues display anti-angiogenic activity independently of immunomodulatory effects. $\mathrm{Br}$ J Cancer 87: 1166-1172

Folkman J (1971) Tumor angiogenesis: therapeutic implications. N Engl J Med 285: $1182-1186$

Freedman VH, Shin SI (1974) Cellular tumorigenicity in nude mice: correlation with cell growth in semi-solid medium. Cell 3: 355-359

Galustian C, Labarthe MC, Bartlett JB, Dalgleish AG (2004) Thalidomidederived immunomodulatory drugs as therapeutic agents. Expert Opin Biol Ther 4: $1963-1970$

Galustian C, Meyer B, Labarthe MC, Dredge K, Klaschka D, Henry J, Todryk S, Chen R, Muller G, Stirling D, Schafer P, Bartlett JB, Dalgleish AG (2009) The anti-cancer agents lenalidomide and pomalidomide inhibit the proliferation and function of $\mathrm{T}$ regulatory cells. Cancer Immunol Immunother 58: $1033-1045$

Gu Y, Li H, Miki J, Kim KH, Furusato B, Sesterhenn IA, Chu WS, McLeod DG, Srivastava S, Ewing CM, Isaacs WB, Rhim JS (2006) Phenotypic characterization of telomerase-immortalized primary non-malignant and malignant tumor-derived human prostate epithelial cell lines. Exp Cell Res 312: $831-843$

Hanahan D, Weinberg RA (2000) The hallmarks of cancer. Cell 100: 57 - 70 
Haslett PA, Hanekom WA, Muller G, Kaplan G (2003) Thalidomide and a thalidomide analogue drug costimulate virus-specific CD8+ T cells in vitro. J Infect Dis 187: 946 - 955

Hayashi T, Hideshima T, Akiyama M, Podar K, Yasui H, Raje N, Kumar S, Chauhan D, Treon SP, Richardson P, Anderson KC (2005) Molecular mechanisms whereby immunomodulatory drugs activate natural killer cells: clinical application. Br J Haematol 128: $192-203$

Hiratsuka S, Nakamura K, Iwai S, Murakami M, Itoh T, Kijima H, Shipley JM, Senior RM, Shibuya M (2002) MMP9 induction by vascular endothelial growth factor receptor-1 is involved in lung-specific metastasis. Cancer Cell 2: 289-300

Jaeger TM, Weidner N, Chew K, Moore DH, Kerschmann RL, Waldman FM, Carroll PR (1995) Tumor angiogenesis correlates with lymph node metastases in invasive bladder cancer. J Urol 154: 69-71

Kalmadi S, Davis M, Dowlati A, O'Keefe S, Cline-Burkhardt M, Pelley RJ, Borden E, Dreicer R, Bukowski R, Mekhail T (2007) Phase I trial of threeweekly docetaxel, carboplatin and oral lenalidomide (Revlimid) in patients with advanced solid tumors. Invest New Drugs 25: $211-216$

Khanna C, Hunter K (2005) Modeling metastasis in vivo. Carcinogenesis 26: $513-523$

Komorowski J, Jerczyńska H, Siejka A, Barańska P, Ławnicka H, Pawłowska Z, Stepień H (2006) Effect of thalidomide affecting VEGF secretion, cell migration, adhesion and capillary tube formation of human endothelial EA.hy 926 cells. Life Sci 78: 2558-2563

Kumar S, Witzig TE, Dispenzieri A, Lacy MQ, Wellik LE, Fonseca R, Lust JA, Gertz MA, Kyle RA, Greipp PR, Rajkumar SV (2004) Effect of thalidomide therapy on bone marrow angiogenesis in multiple myeloma. Leukemia 18: 624-627

Laemmli UK (1970) Cleavage of structural proteins during the assembly of the head of bacteriophage T4. Nature 227: 680-685

Liu W, Nizar S, Dalgleish A (2009a) Gemcitabine and lenalidomide combination in a patient with metastatic pancreatic cancer - a case study. Med Oncol (e-pub ahead of print 12 May 2009; doi:10.1007/s12032009-9228-6)

Liu WM, Laux H, Henry J, Bolton T, Dalgleish A, Galustian C (2009b) A microarray study of altered gene expression in colorectal cancer cells after treatment with immunomodulatory drugs: differences in action in vivo and in vitro. Mol Biol Rep (e-pub ahead of print 14 July 2009; doi:10.1007/s11033-009-9614-3)

Liu WM, Lawrence AJ, Joel SP (2002) The importance of drug scheduling and recovery phases in determining drug activity. Improving etoposide efficacy in BCR-ABL-positive CML cells. Eur J Cancer 38: 842-850

Liu WM, Strauss SJ, Chaplin T, Shahin S, Propper DJ, Young BD, Joel SP, Malpas JS (2004) s-Thalidomide has a greater effect on apoptosis than angiogenesis in a multiple myeloma cell line. Hematol J 5: $247-254$

Mangiameli DP, Blansfield JA, Kachala S, Lorang D, Schafer PH, Muller GW, Stirling DI, Libutti SK (2007) Combination therapy targeting the tumor microenvironment is effective in a model of human ocular melanoma. J Transl Med 5: 38

Melchert M, Kale V, List A (2007) The role of lenalidomide in the treatment of patients with chromosome $5 \mathrm{q}$ deletion and other myelodysplastic syndromes. Curr Opin Hematol 14: 123-129

Mitsiades N, Mitsiades CS, Poulaki V, Chauhan D, Richardson PG, Hideshima T, Munshi NC, Treon SP, Anderson KC (2002) Apoptotic signaling induced by immunomodulatory thalidomide analogs in human multiple myeloma cells: therapeutic implications. Blood 99: 4525-4530

Mustonen T, Alitalo K (1995) Endothelial receptor tyrosine kinases involved in angiogenesis. J Cell Biol 129: 895-898

Reddy KB, Nabha SM, Atanaskova N (2003) Role of MAP kinase in tumor progression and invasion. Cancer Metastasis Rev 22: 395-403

Saad RS, Liu YL, Nathan G, Celebrezze J, Medich D, Silverman JF (2004) Endoglin (CD105) and vascular endothelial growth factor as prognostic markers in colorectal cancer. Mod Pathol 17: 197-203

Shalapour S, Zelmer A, Pfau M, Moderegger E, Costa-Blechschmidt C, van Landeghem FK, Taube T, Fichtner I, Bührer C, Henze G, Seeger K, Wellmann S (2006) The thalidomide analogue, CC-4047, induces apoptosis signaling and growth arrest in childhood acute lymphoblastic leukemia cells in vitro and in vivo. Clin Cancer Res 12: 5526-5532

Sharma RA, Steward WP, Daines CA, Knight RD, O’Byrne KJ, Dalgleish AG (2006) Toxicity profile of the immunomodulatory thalidomide analogue, lenalidomide: phase I clinical trial of three dosing schedules in patients with solid malignancies. Eur J Cancer 42: 2318-2325

Shibuya M (2001) Structure and function of VEGF/VEGF-receptor system involved in angiogenesis. Cell Struct Funct 26: 25-35

Shin SI, Freedman VH, Risser R, Pollack R (1975) Tumorigenicity of virustransformed cells in nude mice is correlated specifically with anchorage independent growth in vitro. Proc Natl Acad Sci 72: 4435-4439

Stirling D (2001) Thalidomide: a novel template for anticancer drugs. Semin Oncol 28: $602-606$

Verhelle D, Corral LG, Wong K, Mueller JH, Moutouh-de Parseval L, Jensen-Pergakes K, Schafer PH, Chen R, Glezer E, Ferguson GD, LopezGirona A, Muller GW, Brady HA, Chan KW (2007) Lenalidomide and CC-4047 inhibit the proliferation of malignant B cells while expanding normal CD34+ progenitor cells. Cancer Res 67: 746-755

Weber DM, Chen C, Niesvizky R, Wang M, Belch A, Stadtmauer EA, Siegel D, Borrello I, Rajkumar SV, Chanan-Khan AA, Lonial S, Yu Z, Patin J, Olesnyckyj M, Zeldis JB, Knight RD, Multiple Myeloma (009) Study Investigators (2007) Lenalidomide plus dexamethasone for relapsed multiple myeloma in North America. N Engl J Med 357: 2133 - 2142

Weidner N, Carroll PR, Flax J, Blumenfeld W, Folkman J (1993) Tumor angiogenesis correlates with metastasis in invasive prostate carcinoma. Am J Pathol 143: $401-409$

Weidner N, Semple JP, Welch WR, Folkman J (1991) Tumor angiogenesis and metastasis -correlation in invasive breast carcinoma. $N$ Engl J Med 324: $1-8$

Wu A, Scheffler MR (2004) Multiple-dose pharmacokinetics and safety of CC-5013 in 15 multiple myeloma patients. J Clin Oncol 22: 2056

Wu L, Adams M, Carter T, Chen R, Muller G, Stirling D, Schafer P, Bartlett JB (2008) Lenalidomide enhances natural killer cell and monocytemediated antibody-dependent cellular cytotoxicity of rituximab-treated CD20+ tumor cells. Clin Cancer Res 14: 4650-4657

Yancopoulos GD, Davis S, Gale NW, Rudge JS, Wiegand SJ, Holash J (2000) Vascular-specific growth factors and blood vessel formation. Nature 407: $242-248$

Yuan A, Yang PC, Yu CJ, Lee YC, Yao YT, Chen CL, Lee LN, Kuo SH, Luh KT (1995) Tumor angiogenesis correlates with histologic type and metastasis in non-small-cell lung cancer. Am J Respir Crit Care Med 152: $2157-2162$ 